\section{The emergence of epidemic dengue fever and dengue hemorrhagic fever in the Americas: a case of failed public health policy}

\section{Duane Gubler ${ }^{1}$}

Director, Asia-Pacific Institute of Tropical Medicine \& Infectious Diseases, Honolulu, Hawaii. Correspondence should be sent to: Dr. Duane Gubler, John A. Burns School of Medicine, University of Hawaii, 3675 Kilauea Ave., Honolulu, HI 96816. E-mail: dgubler@hawaii.edu
A global pandemic of dengue fever (DF) and dengue hemorrhagic fever (DHF) began in Southeast Asia during World War II and in the years following that conflict (1). In the last 25 years of the 20th century the pandemic intensified, with increased geographic spread of both the viruses and the principal mosquito vector, Aedes aegypti. This led to larger and more frequent epidemics and to the emergence of DHF as tropical countries and regions became hyperendemic with the co-circulation of multiple virus serotypes.

With the exception of sporadic epidemics in the Caribbean islands, dengue and yellow fever were effectively controlled in the Americas from 1946 until the late 1970s as a result of the Ae. aegypti eradication program conducted by the Pan American Health Organization (PAHO) $(1,2)$. This was a vertically structured, paramilitary program that focused on mosquito larval control using source reduction and use of insecticides, primarily dichlorodiphenyltrichloroethane (DDT). This highly successful program, however, was disbanded in the early 1970s because there was no longer a perceived need and there were competing priorities for resources; control of dengue and yellow fever was thereafter merged with malaria control. Another major policy change at that time was the use of ultra-low-volume space sprays for killing adult mosquitoes (adulticides) as the recommended method to control Ae. aegypti and thus prevent and control DF and DHF. Both of these decisions were major policy failures because they were ineffective in preventing the re-emergence of epidemic DF and the emergence of DHF in the Region. During the 1970s and 1980s, Ae. aegypti re-infested all of the countries from which it had been eliminated (3). Generally, within a few years of reinfestation a country experienced epidemic DF, followed by the emergence of DHF as the countries became hyperendemic. Alarms about this trend were sounded (3-8), and two international health agencies, the United States Centers for Disease Control and Prevention (CDC) and PAHO, responded by working together to develop laboratory-based surveillance activities and programs for prevention and control $(3,7,9)$.

A major focus of these activities was in Puerto Rico, where the CDC had established a laboratory devoted to surveillance, prevention, and control of DF and DHF (3). This group, in collaboration with the Puerto Rico Health Department (PRHD) and PAHO, sponsored the First International Seminar on Dengue Hemorrhagic Fever in the Americas in June 1985, to highlight the importance of this disease and the increasing threat it posed to the Region (7). This group also developed a new strategy for the prevention and control of epidemic DF and DHF, with five basic components: (1) Active, laboratory-based surveillance, (2) emergency preparedness and response for mosquito control, (3) emergency hospitalization and treatment of DHF patients, (4) education of the medical community on the clinical diagnosis and management of DHF, and (5) integrated, community-based Ae. aegypti control $(3,10)$. It was this plan that gave rise to PAHO's Guidelines for prevention and control of DHF (9) and to the current World Health Organization's Global Strategy for the Prevention and Control of Dengue Fever and Dengue Haemorrhagic Fever (11).

PAHO was proactive in encouraging and helping its Member States develop prevention and control plans for DF and DHF through the 1980s and 1990s, and most countries responded by developing such plans. In 1993, the CDC 
and PAHO developed an emergency plan in response to the possible reintroduction of dengue virus 3 (DENV-3), which had been absent from the Region for 16 years, and the plan was circulated to Member States, who were urged to make preparations to implement it. In April 1994, PAHO issued an alert regarding the reintroduction of DENV-3 in the Region, but there was little response on the part of the countries. As it turns out, a strain of DENV-3 with high epidemic potential was introduced in 1994 and spread throughout Central America and Mexico in 1995, causing major epidemics of DF and DHF (12). Unfortunately, the emergency response plan was not implemented in any country before epidemic transmission took place.

\section{FAILED PUBLIC HEALTH POLICY}

The articles by Rigau-Pérez and Clark, Pérez-Guerra, et al., and Panagos, et al. (13-15) in this issue of Revista Panamericana de Salud Pública/Pan American Journal of Public Health underscore a major policy failure on the parts of ministries of health in dengue-endemic countries of the Americas. Despite leadership, guidance, and help by PAHO and the CDC to develop prevention and control plans, most countries in the Region failed to implement these plans, even though there were repeated and accurate warnings regarding epidemic DF and DHF. When epidemics did occur, the response was normally to apply adulticides via ultra-low-volume space sprays, a method that is expensive and has little or no impact on transmission $(3,16)$. As a result, over the past 25 years the Region has seen hundreds of thousands of cases of DF, tens of thousands of cases of DHF, hundreds of deaths, and hundreds of millions of dollars in economic loss.

Puerto Rico is a case in point. Host of the CDC Dengue Branch Laboratory and partner in many of the early developmental programs to prevent epidemic DF and DHF, Puerto Rico has for 25 years failed to implement an effective DF and DHF prevention and control program. The CDC Dengue Branch Laboratory, in partnership with the Puerto Rico Department of Health (PRDH), developed the best surveillance system in the world in the early 1980s, successfully predicting the DF and DHF epidemics of 1986, 1994 and 1998, each several months prior to peak transmission (3, 17-20). Yet in 1986 and 1994, little was done to implement effective emergency control until after peak transmission had been reached $(17,19,21)$. It wasn't until 1998 that the PRDH actively responded to the surveillance data and implemented community-based emergency control in July, well in advance of peak transmission. An intensive public outreach program that involved the media, civic organizations such as Rotary International, and the mayors of the cities of Puerto Rico focused on community participation to clean up the environment and control mosquito larval habitats. Preliminary data suggested that this approach was effective, but this epidemic was interrupted by Hurricane Georges, so it was not possible to determine whether the communitybased control measures were effective (20). Although the surveillance program is still in place and among the best in the world, the community-based, integrated mosquito control program has never been implemented. Thus, 20 years after the program was started in Puerto Rico in 1985, there is still no effective DF and DHF prevention and control program in place.

In addition to the successful hemispheric Ae. aegypti eradication program from 1946 to 1970, there was one successful prevention program in the American Region. After the 1981 epidemic of DF and DHF in Cuba (21), that country successfully controlled Ae. aegypti for 16 years. It should be noted, however, that the initial success of this program was achieved by the unprecedented 
use of insecticides combined with a vertically structured paramilitary organization with thousands of inspectors going from house to house checking for mosquito breeding sites (22). Unfortunately, the "top down" approach used in Cuba, combined with economic problems, led to failure of the program in 1997, when another epidemic of DF and DHF occurred. Since then, there have been several other such epidemics in Cuba.

It is uncertain why dengue-endemic countries have failed to develop and implement effective prevention and control programs, despite leadership by PAHO and the dramatic emergence of epidemic DHF in the 1980s and 1990s. Clearly, the sporadic nature of dengue epidemics and the misguided reliance on using insecticidal space sprays to kill adult mosquitoes prevented most countries from developing and implementing programs that focused on larval mosquito control, which were much more difficult to implement and maintain. Also, DF and DHF have not been considered priority health problems by the people (14, 15 ) or by government policy makers in most countries. Until there is a change in priorities and governments develop the political will to devote the resources to sustainable Ae. aegypti control, public health policy relating to DF and DHF will continue to be a failure $(3,9-11)$.

\section{REFERENCES}

1. Gubler DJ. Chapter 2: Dengue and dengue hemorrhagic fever: its history and resurgence as a global public health problem. In: Gubler DJ, Kuno G, eds. Dengue and dengue hemorrhagic fever. London: CAB International; 1997. Pp. 1-22.

2. Schliessman DJ, Calheiros LB. A review of the status of yellow fever and Aedes aegypti eradication programs in the Americas. Mosquito News. 1974;34:1-9.

3. Gubler DJ. Aedes aegypti and Aedes aegypti-borne disease control in the 1990s: top down or bottom up. Am J Trop Med Hyg. 1989;40:571-8.

4. Pan American Health Organization. Dengue in the Caribbean, 1977: proceedings of workshop in Montego Bay, Jamaica, May 8-11, 1978. Washington, D.C.: PAHO; 1979. (PAHO Publication 375).

5. Morrens DM, Rigau-Perez JG, Lopez-Correa RH, Moore CG, Ruiz-Tiben EE, Sather GE, et al. Dengue in Puerto Rico, 1977: public health response to characterize and control an epidemic of multiple serotypes. Am J Trop Med Hyg. 1986;35:197-211.

6. Gubler DJ. The re-emergence of vector-borne diseases. Highlights of Medical Entomology Lecture, Entomological Society of America, Washington, D.C., November 1980.

7. Gubler DJ, Casta-Velez A. First International Seminar on Dengue Hemorrhagic Fever in the Americas, San Juan, Puerto Rico, June 1985.

8. Gubler DJ. Dengue and dengue hemorrhagic fever in the Americas. P R Health Sci J. 1987;6: 107-11.

9. Pan American Health Organization. Dengue and dengue haemorrhagic fever in the Americas: guidelines for prevention and control. Washington, D.C.: PAHO; 1994. (PAHO Publication 548).

10. Gubler DJ, Casta-Velez A. A program for the prevention and control of epidemic dengue and dengue hemorrhagic fever in Puerto Rico and the U.S. Virgin Islands. Bull Pan Am Health Organ. 1991;25:237-47.

11. World Health Organization. Strengthening implementation of the global strategy for dengue fever/dengue haemorrhagic fever prevention and control. Report of the informal consultation, Geneva, 18-20 October 1990. Geneva: WHO; 1999. (WHO/CDS/ (DEN)/IC/2001.1).

12. Pinheiro FP, Corber SJ. Global situation of dengue and dengue hemorrhagic fever, and its emergence in the Americas. World Health Stat Q. 1997;50:161.

13. Rigau-Pérez JG, Clark GG. Cómo responder a una epidemia de dengue: visión global y experiencia en Puerto Rico. Rev Panam Salud Publica. 2005;17(4):282-93.

14. Pérez-Guerra CL, Seda H, García-Rivera EJ, Clark GG. Knowledge and attitudes in Puerto Rico concerning dengue prevention. Rev Panam Salud Publica. 2005;17(4):243-53.

15. Panagos A, Lacy ER, Gubler DJ, Macpherson CNL. Dengue in Grenada. Rev Panam Salud Publica. 2005;7(4)225-9.

16. Castle T, Amador M, Rawlins S, Figueroa JP, Reiter P. Absence of impact of aerial malathion treatment on Aedes aegypti during a dengue outbreak in Kingston, Jamaica. Rev Panam Salud Publica. 1999;5(2):100-5.

17. Dietz V, Gubler DJ, Ortiz S, Kuno G, Casta-Velez A, Sather GE, et al. The 1986 dengue and dengue hemorrhagic fever epidemic in Puerto Rico: epidemiologic and clinical observations. P R Health Sci J. 1996;15:201-10. 
18. Rigau-Perez JG, Gubler DJ. Chapter 19: Surveillance for dengue and dengue hemorrhagic fever. In: Gubler DJ, Kuno G, eds. Dengue and dengue hemorrhagic fever. London: CAB International; 1997. Pp. 405-23.

19. Rigau-Perez JG, Vorndam AV, Clark GG. The dengue and dengue hemorrhagic fever epidemic in Puerto Rico, 1994-1995. Am J Trop Med Hyg. 2001;64:67-74.

20. Rigau-Perez JG, Ayala-Lopez A, Garcia-Rivera EJ, Hudson SM, Vorndam V, Reiter P, et al. The reappearance of dengue- 3 and subsequent dengue- 4 and dengue- 1 epidemics, Puerto Rico, 1998. Am J Trop Med Hyg. 2002;67:355-62.

21. Kouri GP, Guzman MG, Bravo JR, Triana C. Dengue haemorrhagic fever/dengue shock syndrome: lessons from the Cuban epidemic, 1981. Bull World Health Organ. 1989;67:375-80.

22. Guzmán MA, Triana C, Bravo J, Kourí G. Estimación de las afectaciones económicas causadas como consecuencia de la epidemia de dengue hemorrágico ocurrida en Cuba en 1981. Rev Cubana Med Trop. 1992;44:13-7.

The health of the people is really the foundation upon which all their happiness and all their powers as a state depend.

[La salud de un pueblo es en realidad la base de toda su felicidad y de todo su poder como estado.]

Benjamin Disraeli 